\title{
Human Corticotropin-releasing Factor plus Lysine Vasopressin Test during Glucocorticoid Therapy
}

\author{
Kozo Hashimoto, Shuso Suemaru, Toshihiro Takao, Masanori Sugawara, Teruhiko Hattori, \\ Jingo Kageyama, Kayo Takahashi, and Zensuke Ota \\ Third Department of Internal Medicine, Okayama University Medical School, Okayama 700, Japan
}

\begin{abstract}
$1.0 \mu \mathrm{g} / \mathrm{kg}$ body wt human corticotropin-releasing factor (hCRF) and 0.005 IU/kg body wt lysine vasopressin (LVP) were administered in a bolus dose to patients receiving daily or alternate-day glucocorticoid therapy. In normal subjects with this hCRF-LVP test, the plasma ACTH increment was signifcantly greater $(\sim 2.5$-fold $) 15 \mathrm{~min}$ after injection than under the CRF test. In patients receiving daily glucocorticoid therapy (>15 mg prednisolone or an equivalent daily dose), the plasma ACTH and cortisol responses to hCRF-LVP were suppressed 2 wk to 1 mo after the beginning of glucocorticoid administration but partially improved at 2-10 mo, and was markedly suppressed several years later. On the other hand, in patients receiving alternate-day glucocorticoid therapy, the plasma ACTH response was normal at $2 \mathrm{wk}$, normal or higher at 1-3 mo, and normal after $4 \mathrm{mo}$. A normal plasma cortisol response was observed throughout the test period in patients receiving alternate-day therapy after pulse therapy, whereas plasma cortisol response was gradually improved in patients receiving alternate-day therapy after several months of daily therapy.
\end{abstract}

\section{Introduction}

Since Vale and his co-workers $(1,2)$ reported on the sequence analysis and synthesis of ovine and rat hypothalamic corticotropin-releasing factor (CRF) ${ }^{1}$ and Shibahara et al. (3) showed that the structure of human CRF (hCRF) was the same as that of rat CRF, the ovine CRF- and hCRF-stimulating tests have been used to examine pituitary-adrenal function in various clinical disorders (4-6). We observed that hCRF alone did not produce sufficient pituitary-adrenocortical response in some normal subjects. In vivo (7) and in vitro (8) studies have shown that vasopressin acts synergistically with CRF to release ACTH from the anterior pituitary. Therefore, we developed a hCRF-lysine vasopressin (LVP) test in which a low dose of LVP was added to hCRF. Here, we examined the responsiveness of this test on the pituitary-adrenocortical axis of patients receiving daily or alternate-day glucocorticoid therapy.

Address reprint requests to Dr. Kozo Hashimoto, Third Department of Internal Medicine, Okayama University Medical School, 2-5-1 Shikata-cho, Okayama 700, Japan.

Received for publication 6 March 1987 and in revised form 15 January 1988.

1. Abbreviations used in this paper: CRF, corticotropin-releasing factor; hCRF, human corticotropin-releasing factor; LVP, lysine vasopressin.

J. Clin. Invest.

(c) The American Society for Clinical Investigation, Inc. 0021-9738/88/07/0013/04 \$2.00

Volume 82, July $1988,13-16$

\section{Methods}

Subjects. The hCRF test and LVP test were performed in five normal subjects. The hCRF-LVP test was performed in 12 normal subjects and 15 tests were performed on 12 autoimmune, renal, and sarcoidosis patients (mean age $\pm \mathrm{SD}, 35.4 \pm 14.4 \mathrm{yr}$; range, $15-49 \mathrm{yr}$ ), who received daily glucocorticoid therapy ( $>15 \mathrm{mg}$ prednisolone or an equivalent daily) for 2 wk to several years (daily therapy). The tests were conducted $24 \mathrm{~h}$ after prednisolone administration. 21 tests were performed in nine patients with renal disease (mainly nephrotic syndrome) (mean age $\pm \mathrm{SD}, 28.2 \pm 14.3 \mathrm{yr}$, range $16-48 \mathrm{yr}$ ) who were administered $>30$ $\mathrm{mg}$ of prednisolone every other day (alternate-day therapy) for 2 wk to $13 \mathrm{mo}$. Alternate-day therapy was started after pulse therapy $(1 \mathrm{~g} / \mathrm{d}$ methylprednisolone for $3 \mathrm{~d})$ and 5-7 d daily steroid therapy $(40 \mathrm{mg} / \mathrm{d})$ in six patients and after several months of daily steroid therapy in three patients. These tests were performed $48 \mathrm{~h}$ after the last dose of prednisolone and just before the next prednisolone administration. None of the patients had a significant reduction in hepatic or renal function.

Tests. Human CRF was purchased from Peptide Institute, Inc. (Osaka, Japan). It was dissolved in a vehicle composed of $0.1 \%$ HSA, 2 $\mathrm{mM} \mathrm{HCl}, 1 \mathrm{mM}$ ascorbic acid, and physiological saline, and put into ampules $(80 \mu \mathrm{g} / 0.8 \mathrm{ml}$ per ampule) after filtration through $0.22-\mu \mathrm{m}$ filters (Millipore/Continental Water Systems, Bedford, MA). LVP was donated by Sandoz Ltd. (Basel, Switzerland) and dissolved in the same vehicle and put into ampules ( $1 \mathrm{IU} / \mathrm{ml}$ per ampule). They were stored frozen at $-20^{\circ} \mathrm{C}$

In the hCRF test, $1.0 \mu \mathrm{g} / \mathrm{kg}$ body wt hCRF i.v. was injected. In the LVP test, $0.005 \mathrm{IU} / \mathrm{kg}$ body wt LVP i.v. was injected. In the hCRFLVP test, $1.0 \mu \mathrm{g} / \mathrm{kg}$ body wt hCRF and $0.005 \mathrm{IU} / \mathrm{kg}$ body wt LVP were mixed and injected in an intravenous bolus dose at 9:00 a.m. after a basal blood sample collection. Blood samples were collected into chilled plastic tubes containing EDTA at $15,30,60,90$, and 120 min after injection for the plasma ACTH and cortisol assays.

Hormone assays. Plasma ACTH and cortisol were measured by RIA using the ACTH-RIA kit (CEA-IRE-Sorin, Gif-sur-Yvette, France) and Sectionary processed antibody coating cortisol-RIA kit (Dai-ichi Radioisotope Lab, Tokyo, Japan), respectively.

Analysis of data. In normal subjects, the responses from the hCRF-LVP test were compared with those from the hCRF test. Increments from the baseline to the peak and the areas under the response curve (above the basal value) calculated by trapezoidal integration were used as parameters for comparisons. Patients receiving glucocorticoid therapy daily were separated into three groups according to the ACTH response patterns, namely, 2 wk to $1 \mathrm{mo}, 2-10 \mathrm{mo}$, and several years. Patients receiving alternate-day glucocorticoid therapy were separated into four groups, namely, $2 \mathrm{wk}, 1 \mathrm{mo}, 2-3 \mathrm{mo}$, and 4-13 mo. Responses on the hCRF-LVP test from normal subjects were compared with those from patients receiving daily and alternate-day therapy. Basal levels and increments of plasma ACTH and cortisol were compared with those of normal subjects. The statistical analysis was conducted by $t$ test.

\section{Results}

Normal subjects. In normal subjects, mean plasma ACTH showed a peak at $30 \mathrm{~min}$ and plasma cortisol at $60 \mathrm{~min}$ in response to hCRF (Fig. 1). Neither plasma ACTH nor cortisol 

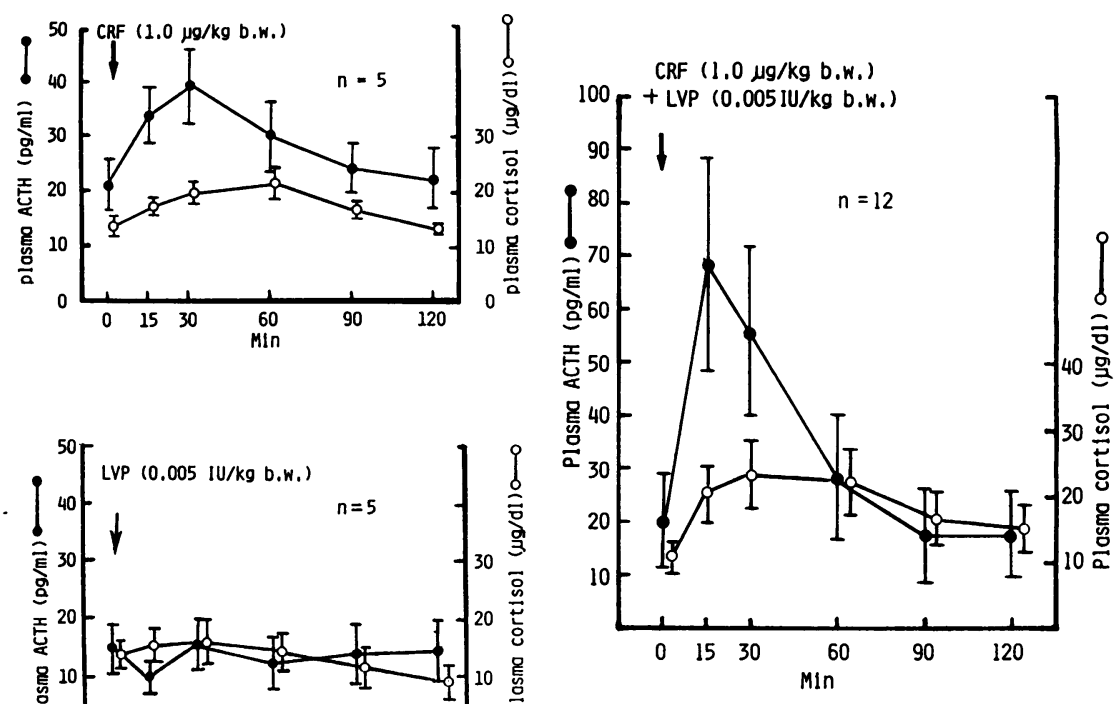

Figure 1. Plasma ACTH and cortisol response to $1 \mu \mathrm{g} / \mathrm{kg}$ body wt human CRF, $0.005 \mathrm{IU} / \mathrm{kg}$ body wt LVP, and $1 \mu \mathrm{g} / \mathrm{kg}$ body wt human CRF plus $0.005 \mathrm{IU} / \mathrm{kg}$ body wt LVP in normal subjects. The points and vertical lines represent mean \pm SEM.

showed a significant response to a low dose of LVP throughout the test period. Plasma ACTH showed a more rapid and marked response to hCRF and LVP than to hCRF-alone, with a peak at $15 \mathrm{~min}$ (Fig. 1, Table I). In the hCRF-LVP test, the $\mathrm{ACTH}$ increment from the baseline to the peak was significantly greater $(\sim 2.5$-fold $)$ than that seen in the hCRF test. The mean value of the ACTH area under the response curve (above the basal values) in the hCRF-LVP test was also greater than that in the hCRF test. On the other hand, no significant difference in the plasma cortisol response was found between the hCRF-LVP test and the hCRF test, although the mean values of the increment and the response area of the plasma cortisol appeared to be greater in the hCRF-LVP test when compared with the hCRF test.

Daily glucocorticoid therapy. In patients receiving daily glucocorticoid therapy, both the plasma ACTH and cortisol responses were suppressed 2 wk to 1 mo after beginning the glucocorticoid administration, but partially improved at 2-10

Table I. Pituitary-Adrenocortical Responsiveness to hCRF and hCRF-LVP in Normal Human Subjects

\begin{tabular}{lcc}
\hline & CRF test $(n=5)$ & $\begin{array}{c}\text { CRF-LVP test } \\
(n=12)\end{array}$ \\
\hline ACTH & & \\
Peak time $($ min $)$ & $33 \pm 7$ & $15 \pm 0^{*}$ \\
Increment $(p g / m l)$ & $19.9 \pm 2.1$ & $48.1 \pm 3.6^{*}$ \\
$\quad$ Area $(p g /$ min per $m l)$ & $1,049 \pm 172$ & $1,903 \pm 180^{\ddagger}$ \\
Cortisol & & \\
Peak time $($ min $)$ & $48 \pm 7$ & $35 \pm 5$ \\
Increment $(\mu g / d l)$ & $9.0 \pm 3.3$ & $13.2 \pm 1.3$ \\
Area $(\mu g /$ min per $d l)$ & $596 \pm 223$ & $991 \pm 108$ \\
\hline
\end{tabular}

Values are mean $\pm \operatorname{SEM}(n=5)$. Increment, from baseline to peak. Area, under the response curve, above baseline.

${ }^{*} P<0.01$ vs. CRF test, ${ }^{\ddagger} P<0.05$. mo, and were suppressed markedly at several years (Fig. 2, Table II). There was a slight negative correlation between the total dose of glucocorticoid and the plasma cortisol increments $(P<0.05)$.

Alternate-day glucocorticoid therapy. In patients receiving alternate-day glucocorticoid therapy after pulse therapy, mean plasma ACTH increment was normal at $2 \mathrm{wk}$, higher at $1 \mathrm{mo}$, and normal again after 2 mo, whereas mean plasma cortisol increment was normal throughout the treatment period. Basal ACTH levels were low within 3 mo but were normal after 4 mo (Fig. 3, Table II). In alternate-day therapy after long-term daily therapy plasma ACTH response recovered to normal levels, whereas plasma cortisol response remained lowered at 2 wk after starting alternate-day therapy. In these cases at 1-2 mo, the response of plasma ACTH was higher than in normal subjects, whereas plasma cortisol remained lowered. However, the responsiveness of plasma ACTH and cortisol were almost normal after 4 mo (Fig. 3).

\section{Discussion}

Vasopressin acts synergistically with CRF to release ACTH from corticotrophs (7-10). Therefore, the simultaneous administration of CRF and vasopressin was thought to be more helpful than CRF alone for corticotroph stimulation. The LVP test has been used to examine corticotrophic function, in which $\sim$ 4-10 IU LVP was administered intramuscularly or intravenously with a high incidence of side effects. We have observed that even 1 IU of LVP caused side effects to a certain degree. Therefore, we selected $0.005 \mathrm{IU} / \mathrm{kg}$ body wt $(0.25-0.35$ IU per person) as the dose for LVP, in combination with 1.0 $\mu \mathrm{g} / \mathrm{kg}$ body wt hCRF, resulting in diminished side effects and a synergistic effect on the ACTH release.

We chose patients receiving $>15 \mathrm{mg}$ prednisolone daily or $>30 \mathrm{mg}$ prednisolone every other day because of reports in clinical and animal studies showing that the degree of suppression depended on the dose of glucocorticoid (11-15) and that glucocorticoid-induced suppression of the adrenocortical re- 

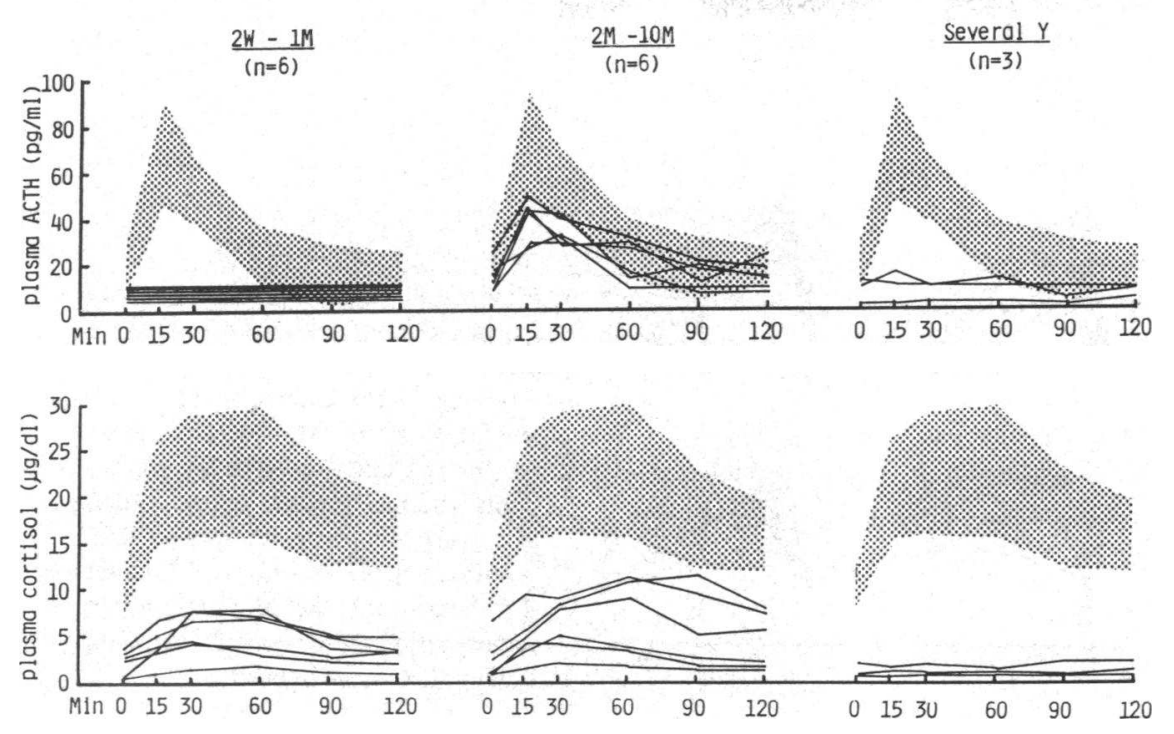

Figure 2. Plasma ACTH and cortisol responses to $1 \mu \mathrm{g} / \mathrm{kg}$ body wt human CRF plus $0.005 \mathrm{IU} / \mathrm{kg}$ body wt LVP in patients receiving glucocorticoid therapy daily for 2 wk to 1 $\mathrm{mo}(n=6), 2-10 \mathrm{mo}(n=6)$, and several years $(n=3)$. The shaded area shows the response range (mean $\pm \mathrm{SD}$ ) of five normal subjects. Abbreviations: $\mathrm{W}$, week; $\mathrm{M}$, month; $\mathrm{Y}$, year.

sponse was observed in the exogenous ACTH-stimulating test in all patients receiving $>15 \mathrm{mg}$ prednisolone daily (16).

It is difficult to compare directly the responses of plasma ACTH and cortisol in patients receiving daily therapy vs. patients receiving alternate-day therapy, as the tests were done at different times after the last glucocorticoid administration (24 vs. $48 \mathrm{~h}$ ). Another purpose of this investigation, however, was to estimate the pituitary-adrenocortical responsiveness in these groups in their most recovered conditions after the last glucocorticoid administration and before the next glucocorticoid administration. Using this test, we could at least compare optimal pituitary-adrenocortical responsiveness in these two groups at the periods when the tests were performed on their steroid therapy.

The severe suppression of the pituitary-adrenocortical response 2 wk to 1 mo after the beginning of steroid administration in patients receiving daily therapy may be ascribed to the negative feedback effect of the very high dose of prednisolone in the beginning (12-15). A gradual decrease in the doses of prednisolone in the therapeutic regimen may have caused the partial improvement in response at 2-10 mo. Glucocorticoid administration for several years seemed to cause a persistent suppression in corticotrophs and an atrophy of the adrenal cortex.

The hyperresponse of the pituitary gland to hCRF-LVP in two patients receiving alternate-day therapy for 2 wk to 2 mo might be explained by the up-regulation of CRF receptors on corticotrophs due to a reduction in endogenous CRF and an increase in the releasable pool of ACTH in recovered corticotrophs. It was revealed that the reserve function of $\mathrm{ACTH}$ and cortisol release was well-maintained in patients receiving alternate-day glucocorticoid therapy, especially in patients receiving therapy after steroid pulse therapy. ACTH release recovered earlier than cortisol release in patients receiving alternate-day therapy after long-term daily therapy. Alternate-day therapy thus had the advantage of causing little suppression of

Table II. Pituitary-Adrenocortical Responsiveness to hCRF-LVP in Patients Receiving Steroid Therapy Daily or on Alternate Days

\begin{tabular}{|c|c|c|c|c|c|c|c|c|}
\hline & \multicolumn{3}{|c|}{ Daily therapy } & \multicolumn{4}{|c|}{ Alternate-day therapy } & \multirow[b]{2}{*}{$\begin{array}{l}\text { Normal subjects } \\
\quad(n=12)\end{array}$} \\
\hline & $\begin{array}{c}2 \mathrm{wk} \text { to } 1 \mathrm{mo} \\
(n=6)\end{array}$ & $\begin{array}{c}2-10 \mathrm{mo} \\
(n=6)\end{array}$ & $\begin{array}{l}\text { Several years } \\
\quad(n=3)\end{array}$ & $\begin{array}{c}2 \mathrm{wk} \\
(n=3)\end{array}$ & $\begin{array}{c}1 \mathrm{mo} \\
(n=4)\end{array}$ & $\begin{array}{l}2-3 \mathrm{mo} \\
(n=5)\end{array}$ & $\begin{array}{c}4-13 \text { mo } \\
(n=2)\end{array}$ & \\
\hline \multicolumn{9}{|c|}{ АСТН $(p g / m l)$} \\
\hline \multirow[t]{2}{*}{ Basal } & $<10^{*}$ & 15.4 & $11.0^{*}$ & 14.0 & 21.3 & 14.3 & 34.3 & 20.6 \\
\hline & & \pm 2.7 & \pm 1.0 & \pm 4.0 & \pm 7.7 & \pm 4.3 & \pm 24.3 & \pm 2.6 \\
\hline \multirow[t]{2}{*}{ Increment } & $0.03^{\ddagger}$ & $24.5^{*}$ & $3.9^{\ddagger}$ & 45.3 & 60.9 & $96.0^{\ddagger}$ & 37.3 & 48.1 \\
\hline & \pm 0.03 & \pm 2.9 & \pm 1.9 & \pm 9.3 & \pm 16.5 & \pm 11.7 & \pm 13.7 & \pm 3.6 \\
\hline \multicolumn{9}{|c|}{ Cortisol $(\mu g / d l)$} \\
\hline \multirow[t]{2}{*}{ Basal } & $2.1^{\ddagger}$ & $2.4^{\ddagger}$ & $0.9^{\ddagger}$ & 15.3 & 15.2 & 9.4 & 10.2 & 11.0 \\
\hline & \pm 0.6 & \pm 0.9 & \pm 0.5 & \pm 3.1 & \pm 1.8 & \pm 3.6 & \pm 0.3 & \pm 0.7 \\
\hline \multirow[t]{2}{*}{ Increment } & $3.3^{*}$ & $4.9^{*}$ & $0.13^{*}$ & 9.1 & 9.3 & 9.9 & 9.8 & 13.2 \\
\hline & \pm 0.9 & \pm 1.0 & \pm 0.07 & \pm 2.1 & \pm 1.2 & \pm 1.7 & \pm 0.7 & \pm 1.3 \\
\hline
\end{tabular}

Alternate-day therapy was started after pulse therapy. Values are mean \pm SEM. Increment, from baseline to peak. $\quad{ }^{*} P<0.01,{ }^{\ddagger} P<0.001$ vs. normal subjects. 

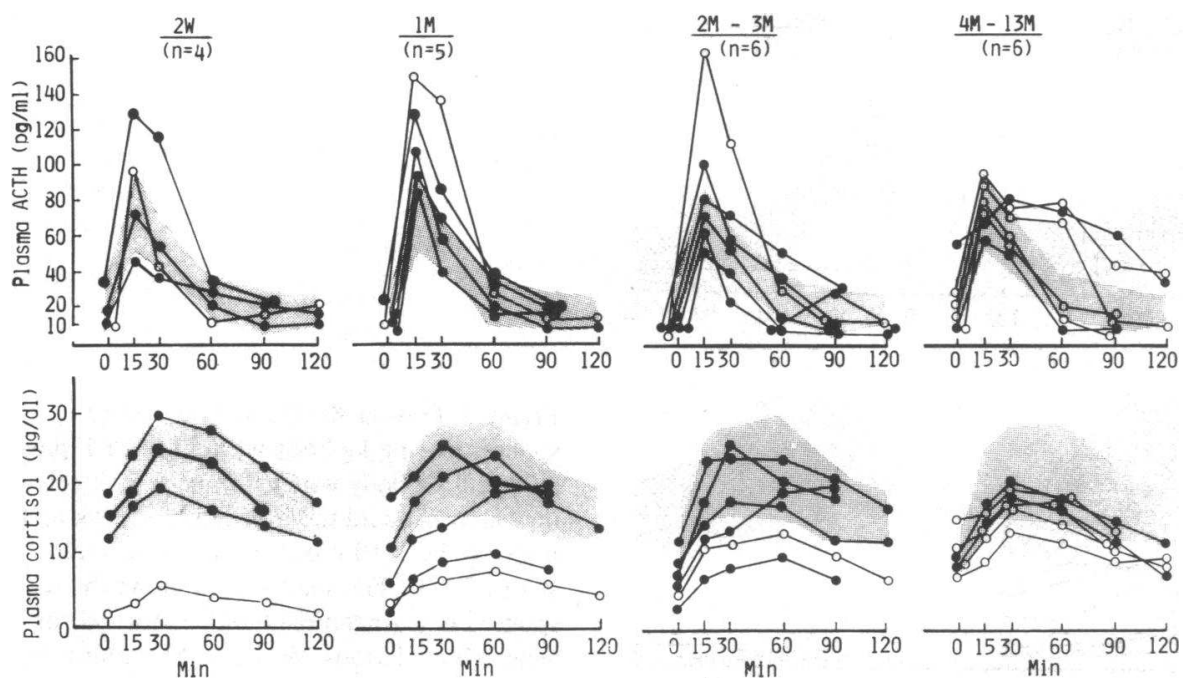

Figure 3. Plasma ACTH and cortisol responses to $1 \mu \mathrm{g} / \mathrm{kg}$ body wt human CRF plus $0.005 \mathrm{IU} / \mathrm{kg}$ body wt LVP in patients receiving alternate-day glucocorticoid therapy for $2 \mathrm{wk}(n=4), 1 \mathrm{mo}(n=5), 2-3$ mo $(n=6)$, and 4-13 mo $(n=6)$. ०, patients who received alternate-day therapy after daily therapy for more than several months. $\bullet$, patients who received alternateday therapy after steroid pulse therapy ( 1 $\mathrm{g} /$ day methyprednisolone for $3 \mathrm{~d}$ ) and 5-7 d daily therapy $(40 \mathrm{mg} / \mathrm{d})$. the pituitary-adrenocortical system. The present results also show that the hCRF-LVP test is a very useful method to examine the pituitary-adrenocortical reserve function.

\section{Acknowledgments}

The authors wish to thank Miss R. Akiyama for assistance in the ACTH and cortisol assays.

This study was supported in part by the Ministry of Health and Welfare Research Committee for Disorders in the Hypothalamo-Pituitary System in Japan.

\section{References}

1. Vale, W., J. Spiess, C. Rivier, and J. Rivier. 1981. Characterization of a 41-residue ovine hypothalamic peptide that stimulates secretion of corticotropin and $\beta$-endorphin. Science (Wash. DC). 213:1394-1397.

2. Rivier, J., J. Spiess, and W. Vale. 1983. Characterization of rat hypothalamic corticotropin-releasing factor. Proc. Natl. Acad. Sci. USA. 80:4851-4855.

3. Shibahara, S., Y. Morimoto, Y. Furutani, M. Notake, H. Takahashi, S. Shimizu, S. Horikawa, and S. Numa. 1983. Isolation and sequence analysis of the human corticotropin-releasing factor precursor gene. EMBO (Eur. Mol. Biol. Organ.) J. 2:775-779.

4. Chrousos, G. P., H. M. Schulte, E. H. Oldfield, P. W. Gold, G. B. Cutler, Jr., and D. L. Loriaux. 1984. The corticotropin-releasing factor stimulation test: an aid in the evaluation of patients with Cushing's syndrome. N. Engl. J. Med. 310:622-626.

5. Hashimoto, K., K. Murakami, T. Hattori, and Z. Ota. 1984. Corticotropin releasing factor (CRF)-stimulating test in patients with disorders of the hypothalamo-pituitary-adrenal axis. Nihon Naika Gakkai Zasshi. 73:1317-1324. (In Japanese.)

6. Shulte, H. M., G. P. Chrousos, P. Avgerinos, P. W. Gold, E. H. Oldfield, G. B. Cutler, Jr., and D. L. Loriaux. 1984. The corticotropin-releasing hormone stimulation test: a possible aid in the evaluation of adrenal insufficiency. J. Clin. Endocrinol. \& Metab. 58:1064-1067.
7. Hashimoto, K., K. Murakami, T. Hattori, and Z. Ota. 1984. Synergistic interaction of corticotropin releasing factor and arginine vasopressin on adrenocorticotropin and cortisol secretion in macaca fuscata. Acta Med. Okayama. 38:261-267.

8. Murakami, K., K. Hashimoto, and Z. Ota. 1984. Interaction of synthetic ovine corticotropin releasing factor and arginine vasopressin on in vitro ACTH release by the anterior pituitary of rats. Neuroendocrinology. 39:49-53.

9. Rivier, C., and W. Vale. 1983. Interaction of corticotropin-releasing factor and arginine vasopressin on adrenocorticotropin secretion in vivo. Endocrinology. 113:939-942.

10. Gillies, G. E., E. A. Linton, and P. J. Lowry. 1982. Corticotropin releasing activity of the new CRF is potentiated several times by vasopressin. Nature (Lond.). 299:355-357.

11. Schulmeyer, T. H., G. C. Tsokos, P. C. Avgerinos, J. E. Balow, R. D'Agata, D. L. Loriaux, and G. P. Chrousos. 1985. Pituitary-adrenal responsiveness to corticotropin-releasing hormone in patients receiving chronic, alternate day glucocorticoid therapy. J. Clin. Endocrinol. \& Metab. 61:22-27.

12. Keller-Wood, M. E., and M. F. Dallman. 1984. Corticosteroid inhibition of ACTH secretion. Endocr. Rev. 5:1-24.

13. Fehm, H. L., K. H. Voigt, G. Kummer, R. Lang, and E. F. Pfeiffer. 1979. Differential and integral corticosteroid feedback effects on ACTH secretion in hypoadrenocorticism. J. Clin. Invest. 63:247253.

14. Jones, M. T., E. M. Tiptaft, F. R. Brush, D. A. N. Fergusson, and R. L. B. Neame. 1974. Evidence for dual corticosteroid-receptor mechanisms in the feedback control of adrenocorticotropin secretion. J. Endocrinol. 60:223-233.

15. Dallman, M. F., and F. E. Yates. 1969. Dynamic asymmetries in the corticosteroid feedback path and distribution-metabolism-binding elements of the adrenocortical system. Ann. NY Acad. Sci. 156:696-721.

16. Hashimoto, K., M. Mori, K. Asaoka, and T. Ofuji. 1973. Adrenocortical responsiveness to synthetic 1-24 ACTH in patients receiving synthetic glucocorticoid therapy. Horumon to Rinsho. 21:1151-1155 (In Japanese.). 